\title{
Clinical and Prognostic Features of Rectal Neuroendocrine Tumors
}

\author{
Brett Weinstock $^{\mathrm{a}}$ Stephen C. Ward ${ }^{\mathrm{b}}$ Noam Harpaz ${ }^{\mathrm{b}}$ Richard R.P. Warner ${ }^{\mathrm{a}}$ \\ Steven Itzkowitz ${ }^{a}$ Michelle Kang Kim ${ }^{a}$ \\ a Division of Gastroenterology, Department of Medicine, and ${ }^{b}$ Department of Pathology, Mount Sinai School of \\ Medicine, New York, N.Y., USA
}

\section{Key Words}

Rectal neuroendocrine tumors · Carcinoids · Stage · Grade ·

Size $\cdot$ Prognosis · Survival

\begin{abstract}
Background: Rectal neuroendocrine tumors (NETs) are among the most common NETs. The aim was to validate European Neuroendocrine Tumor Society (ENETS)/North American Neuroendocrine Tumor Society (NANETS) staging and grading systems with regard to clinical outcomes. Methods: A comprehensive database was constructed from existing databases of the Mount Sinai Division of Gastrointestinal Pathology and the Carcinoid Cancer Foundation. Analysis was performed on 141 patients identified with rectal NETs seen at Mount Sinai Hospital between 1972 and 2011. Results: The median age was 52.7 years; $43 \%$ were males. Average tumor size was $0.88 \mathrm{~cm}$. NETs $<1 \mathrm{~cm}$ accounted for $75.6 \%$ of the tumors. Stage I, II, III and IV accounted for 79.4, 2.8, 5.0 and $12.8 \%$ of the tumors, respectively. G1 tumors accounted for $88.1 \%$, G2 $8.3 \%$ and G3 3.6\%. Of G1 tumors, $94.6 \%$ were stage I and $5.4 \%$ were stage IV. The median survival time for all 141 patients was 6.8 years (range, $0.8-34.7$ years). The overall 5 -year survival rate was $84.4 \%$. The 5 -year survival rates for patients in stages I-IV were 92.7, 75.0, 42.9 and $33.2 \%$, respectively. The 5 -year survival rates for patients with G1-G3 tumors were $87.7,47.6$ and $33.3 \%$, respectively.
\end{abstract}

Univariate analysis of increased survival showed significance for lower stage, lower grade, smaller size, absence of symptoms and endoscopically treated tumors. Multivariate analysis showed that stage alone was statistically significant as the strongest predictor of survival. Conclusion: The results of our study validated ENETS/NANETS guidelines for staging and grading of rectal NETs in the US setting of a tertiary referral center. Staging according to ENETS/NANETS guidelines should be used in the treatment algorithm rather than size alone.

(c) 2013 S. Karger AG, Basel

\section{Introduction}

Gastroenteropancreatic neuroendocrine tumors (GEP-NETs) signify the majority of all NETs, traditionally referred to as carcinoid tumors. In a recent study, the rectum was the site of overall highest GEP frequency, representing $17.7 \%$ of neoplasms of all NETs and $29.0 \%$ of GEP-NETs [1]. In another recent study, rectal NETs represented $14 \%$ of GEP-NETs [2]. According to studies using the National Cancer Institute's Surveillance, Epidemiology and End Results registry, the incidence rate of rectal NETs in the US has risen, largely due to an increased number of screening colonoscopies, allowing for identification of smaller lesions $[3,4]$. This trend can be expected to 
Table 1. NANETS tumor and stage guidelines

\begin{tabular}{|c|c|}
\hline \multicolumn{2}{|c|}{ TNM staging } \\
\hline TX & Primary tumor cannot be assessed \\
\hline T0 & No evidence of primary tumor \\
\hline $\mathrm{T} 1$ & $\begin{array}{l}\text { Tumor invades lamina propria or submucosa and size } \\
2 \mathrm{~cm} \text { or less }\end{array}$ \\
\hline T1a & Tumor size $<1 \mathrm{~cm}$ in greatest dimension \\
\hline $\mathrm{T} 1 \mathrm{~b}$ & Tumor size $1-2 \mathrm{~cm}$ in greatest dimension \\
\hline $\mathrm{T} 2$ & $\begin{array}{l}\text { Tumor invades muscularis propria or size }>2 \mathrm{~cm} \text { with } \\
\text { invasion of lamina propria or submucosa }\end{array}$ \\
\hline T3 & $\begin{array}{l}\text { Tumor invades through the muscularis propria into the } \\
\text { subserosa, or into non-peritonealized pericolic or } \\
\text { perirectal tissues }\end{array}$ \\
\hline $\mathrm{T} 4$ & $\begin{array}{l}\text { Tumor invades peritoneum or other organs; for any } \mathrm{T} \text {, } \\
\text { add }(\mathrm{m}) \text { for multiple tumors }\end{array}$ \\
\hline No & No nodal involvement \\
\hline N1 & Nodal involvement \\
\hline M0 & No metastatic disease \\
\hline M1 & Metastatic disease \\
\hline
\end{tabular}

\begin{tabular}{llll}
\hline \multicolumn{2}{l}{ Tumor staging } \\
\hline Stage & T stage & N stage & M stage \\
\hline 0 & T0 & N0 & M0 \\
I & T1a or T1b & N0 & M0 \\
IIA & T2 & N0 & M0 \\
IIB & T3 & N0 & M0 \\
IIIA & T4 & N0 & M0 \\
IIIB & any T & N1 & M0 \\
IV & any T & any N & M1 \\
\hline
\end{tabular}

\begin{tabular}{lll}
\hline \multicolumn{2}{l}{ Tumor grading } \\
\hline Grade & $\begin{array}{l}\text { Mitotic rate per } \\
\text { 10 high-power fields }\end{array}$ & Ki67 index, \% \\
\hline G1 & $<2$ & $<3$ \\
G2 & $2-20$ & $3-20$ \\
G3 & $>20$ & $>20$ \\
\hline
\end{tabular}

continue as colonoscopy continues to be performed in screening for colon cancer [5-7]. A large registry study by Yao et al. [8] cited 5-year overall survivals of 90 and 62\% for localized and regional diseases, respectively. Although patients frequently have excellent survival, these tumors still have a risk of metastasis, mainly to the liver, for whom 5 -year survival drops to $24 \%$ [8-12].

The management of rectal NETs continues to evolve. Clinicians have frequently used tumor size as a guide for further treatment. Most guidelines agree that tumors
$<1 \mathrm{~cm}$ can be appropriately treated by local excision, while tumors $>2 \mathrm{~cm}$ generally require a more invasive surgical procedure. Endoscopic ultrasound may be used to measure tumor size and depth [13]. Some studies suggest that malignant potential increases with increased tumor size and depth $[4,14,15]$.

In 2005, a multidisciplinary team of 57 NET experts developed consensus guidelines at an international conference. These were published in written form as the European Neuroendocrine Tumor Society (ENETS) Consensus Statement in 2007 [16]. From 2009 to 2010, The International Union of Cancer Control, World Health Organization and the American Joint Committee on Cancer adopted the guidelines proposed by ENETS [16-20]. In 2011, Anthony et al. [21] published the North American Neuroendocrine Tumor Society (NANETS) Consensus Guidelines based on ENETS staging guidelines (table 1) $[16,22]$. Essentially, these guidelines are identical. Collectively, these studies define a system for staging and grading NETs of the rectum which characterize tumors based on their size, depth, location, and histologic morphology. For that reason, stage and grade may provide more accurate prognostic information than size alone. A retrospective multi-institution study in Berlin and France validated these criteria [23]. To our knowledge, no such review has been done in the US.

The principal aim of this study was to validate these guidelines in a cohort of patients with rectal NETs seen at a tertiary referral center. A secondary aim was to identify prognostic factors associated with metastatic disease.

\section{Methods}

\section{Data Collection}

This research was approved by the Institutional Review Board at Mount Sinai Hospital in New York, N.Y. We performed a retrospective chart review of 141 patients with a confirmed histopathological and immunohistochemical staining diagnosis of primary rectal NET. Cases were identified by querying existing databases. The Mount Sinai Gastrointestinal Pathology Database is a prospectively maintained database containing pathology records from patients seen at Mount Sinai Hospital. The Carcinoid Cancer Foundation Database has clinicopathological information on over 2,000 patients with NETs. Individual patient records were reviewed to ascertain any other information not available in the database. The data gathered on each patient included demographics, symptoms at presentation, size of tumor, depth of invasion, diagnostic method, treatment method, pathological stains and margins, and follow-up information. Overall survival information was ascertained using medical records and the Social Security Death Index. 
Patient and Tumor Characteristics

Clinicopathologic characteristics were studied and divided into subgroups. Symptoms at presentation were categorized based on chief complaint. In asymptomatic patients undergoing age-appropriate screening colonoscopies, NETs were characterized as incidental findings.

Local treatments included colonoscopy or sigmoidoscopy with biopsy or snare polypectomy, and transanal excision. Regional treatments included surgical approaches such as low anterior resection, abdominoperineal resection, proctocolectomy.

Tumor-node-metastasis (TNM) staging (table 1) was performed in accordance with the established guidelines [16, 19, 24]. Tumors were graded G1, G2, or G3 (table 1) using mitotic rate and Ki67 in accordance with ENETS, NANETS, and American Joint Committee on Cancer guidelines [16, 18, 19, 21, 22]. Slides were retrieved whenever possible $(n=84)$ from the archives and graded by a single pathologist (S.C.W.). Grade was determined by mitotic rate and Ki67; staining for chromogranin A and synaptophysin was performed on diagnosis.

Overall survival was calculated based on the Social Security Death Index.

\section{Statistical Analysis}

Statistical analysis was performed using SPSS (release 18.0.0, PASW Statistics 18, Polar Engineering and Consulting). Comparison of means between paired groups was done using the independent-sample $t$ test. The cutoff for $p$ value significance was $p<0.05$. Univariate and multivariate analysis was performed. Kaplan-Meier curves were constructed and log-rank testing was used to assess survival differences between groups.

\section{Results}

Patient and Tumor Characteristics

We identified 141 patients with rectal NETs. Table 2 presents the demographic and clinicopathologic characteristics of these patients. The median age of patients with primary rectal NET was 52.7 years (range $13-88$; table 2 ), and $43.3 \%(\mathrm{n}=61)$ were male. Of the patients for whom racial data were available, $63.8 \%(\mathrm{n}=44)$ were Caucasian, $13.0 \%(\mathrm{n}=9)$ were Asian, $11.6 \%(\mathrm{n}=8)$ were AfricanAmerican, and $11.6 \%(\mathrm{n}=8)$ were Hispanic.

The average size of primary NET was $0.88 \mathrm{~cm}$. A total of $99(75.6 \%)$ rectal NETs were $<1 \mathrm{~cm}, 14(10.8 \%)$ were $1-2 \mathrm{~cm}$ and $18(13.8 \%)$ were $>2 \mathrm{~cm}$. There were three NETs staged as pT1a $(<1 \mathrm{~cm})$ but were excluded from size analysis because the exact size of tumor was not available.

pT1a NETs accounted for 102 (76.1\%) of the tumors, all of which were found to have no nodal or distant metastases. Stage I, II, III and IV accounted for 79.4, 2.8, 5.0 and $12.8 \%$ of the tumors ( $\mathrm{n}=112,4,7$ and 18$)$, respectively. Grading was available in $84(59.5 \%)$ tumors. G1 tumors accounted for 88.1\%, G2 8.3\%, and G3 3.6\% (n =
Table 2. Clinicopathological characteristics of 141 patients with rectal NETs

\begin{tabular}{|c|c|}
\hline Median age, years & $52.7(13-88)$ \\
\hline \multicolumn{2}{|l|}{ Sex } \\
\hline Male & $61(43.3)$ \\
\hline Female & $80(56.7)$ \\
\hline \multicolumn{2}{|l|}{ Primary symptom } \\
\hline Incidental finding & $98(69.5)$ \\
\hline Change in bowel habits & $18(12.8)$ \\
\hline Rectal bleeding & $9(6.4)$ \\
\hline Abdominal/rectal pain & $7(5.0)$ \\
\hline \multicolumn{2}{|l|}{ Tumor size } \\
\hline Mean, cm & $0.88(0-5.3)$ \\
\hline$<1.0 \mathrm{~cm}$ & $99(75.6)$ \\
\hline $1.0-2.0 \mathrm{~cm}$ & $14(10.8)$ \\
\hline$\geq 2 \mathrm{~cm}$ & $18(13.8)$ \\
\hline \multicolumn{2}{|l|}{$\mathrm{T}$ classification } \\
\hline $\mathrm{Tx}$ & 7 \\
\hline $\mathrm{T} 1 \mathrm{a}$ & $102(75.6)$ \\
\hline $\mathrm{T} 1 \mathrm{~b}$ & $10(7.4)$ \\
\hline $\mathrm{T} 2$ & $4(3.0)$ \\
\hline T3 & $12(8.9)$ \\
\hline $\mathrm{T} 4$ & $7(5.2)$ \\
\hline \multicolumn{2}{|l|}{ Nodal involvement } \\
\hline $\mathrm{Nx}$ & 2 \\
\hline No & $120(86.3)$ \\
\hline N1 & $19(13.7)$ \\
\hline \multicolumn{2}{|l|}{ Distant metastasis } \\
\hline M0 & $123(87.2)$ \\
\hline M1 & $18(12.8)$ \\
\hline \multicolumn{2}{|l|}{ Stage } \\
\hline I & $112(79.4)$ \\
\hline II & $4(2.8)$ \\
\hline III & $7(5.0)$ \\
\hline IV & $18(12.8)$ \\
\hline \multicolumn{2}{|l|}{ Grade } \\
\hline G1 & $74(88.1)$ \\
\hline G2 & $7(8.3)$ \\
\hline G3 & $3(3.6)$ \\
\hline Not available & 57 \\
\hline
\end{tabular}

Figures in parentheses indicate percentage or range.

74,7 and 3). Of G1 tumors, 70 (94.6\%) were stage I and 4 (5.4\%) were stage IV. There were 57 patients for whom grading could not be done due to unavailability of original slides.

There were 123 patients with nonmetastatic disease and 18 patients with metastatic disease (table 3 ). Of the 18 metastatic tumors, the average size was $2.6 \mathrm{~cm}$. This result was significantly larger than the $0.7 \mathrm{~cm}$ for nonmetastatic tumors $(\mathrm{p}<0.001)$. 
Table 3. Comparison of characteristics of nonmetastatic NETs $(\mathrm{n}=123)$ and metastatic NETs $(\mathrm{n}=18)$

\begin{tabular}{lllr}
\hline & $\begin{array}{l}\text { Non- } \\
\text { metastatic } \\
\text { tumors } \\
(\mathrm{M} 0)\end{array}$ & $\begin{array}{l}\text { Distant } \\
\text { metastatic } \\
\text { tumors } \\
(\mathrm{M} 1)\end{array}$ & p value \\
& 52.6 & 56.2 & 0.292 \\
\hline $\begin{array}{l}\text { Mean age, years } \\
\text { Mean tumor size, cm }\end{array}$ & 0.7 & 2.6 & $<0.001$ \\
Symptoms at diagnosis & $23.6 \%$ & $77.8 \%$ & $<0.001$ \\
$\begin{array}{l}\text { Endoscopic treatment } \\
\text { Survival }\end{array}$ & $64.2 \%$ & $28.6 \%$ & 0.006 \\
$\quad$ 5-year survival & & & \\
$\quad$ Total survival to date, years & 7.6 & 5.3 & $<0.001$ \\
\hline
\end{tabular}

Table 4. Clinical characteristics by treatment types

\begin{tabular}{|c|c|c|c|c|}
\hline & $\begin{array}{l}\text { Endoscopy } \\
(n=83)\end{array}$ & $\begin{array}{l}\text { Transanal } \\
\text { resection } \\
(\mathrm{n}=20)\end{array}$ & $\begin{array}{l}\text { Surgery } \\
(n=27)\end{array}$ & $\begin{array}{l}\mathrm{p} \\
\text { value }\end{array}$ \\
\hline \multicolumn{5}{|l|}{ Age } \\
\hline$\leq 60$ years & $64(77 \%)$ & $14(70 \%)$ & $17(63 \%)$ & \multirow[t]{2}{*}{0.335} \\
\hline$>60$ years & $19(23 \%)$ & $6(30 \%)$ & $10(37 \%)$ & \\
\hline \multicolumn{5}{|l|}{ Sex } \\
\hline Male & $49(59 \%)$ & $12(60 \%)$ & $12(44 \%)$ & \multirow[t]{2}{*}{0.386} \\
\hline Female & $34(41 \%)$ & $8(40 \%)$ & $15(56 \%)$ & \\
\hline \multicolumn{5}{|l|}{ Tumor size } \\
\hline$<1.0 \mathrm{~cm}$ & $67(81 \%)$ & $13(68 \%)$ & $12(44 \%)$ & \multirow[t]{3}{*}{0.003} \\
\hline $1-2 \mathrm{~cm}$ & $6(7 \%)$ & $3(16 \%)$ & $3(11 \%)$ & \\
\hline$\geq 2 \mathrm{~cm}$ & $10(12 \%)$ & $3(16 \%)$ & $12(44 \%)$ & \\
\hline \multicolumn{5}{|c|}{ T classification } \\
\hline T1a & $73(90 \%)$ & $12(67 \%)$ & $10(37 \%)$ & \multirow[t]{5}{*}{$<0.001$} \\
\hline $\mathrm{T} 1 \mathrm{~b}$ & $5(6 \%)$ & $2(11 \%)$ & $2(7 \%)$ & \\
\hline $\mathrm{T} 2$ & $0(0 \%)$ & $2(11 \%)$ & $2(7 \%)$ & \\
\hline $\mathrm{T} 3$ & $2(2 \%)$ & $1(6 \%)$ & $9(33 \%)$ & \\
\hline $\mathrm{T} 4$ & $1(1 \%)$ & $1(6 \%)$ & $4(15 \%)$ & \\
\hline \multicolumn{5}{|c|}{ Nodal involvement } \\
\hline N0 & $79(96 \%)$ & $18(90 \%)$ & $14(52 \%)$ & \multirow[t]{2}{*}{$<0.001$} \\
\hline N1 & $3(4 \%)$ & $2(10 \%)$ & $13(48 \%)$ & \\
\hline \multicolumn{5}{|c|}{ Distant metastasis } \\
\hline M0 & $79(95 \%)$ & $16(80 \%)$ & $20(74 \%)$ & \multirow[t]{2}{*}{0.005} \\
\hline M1 & $4(5 \%)$ & $4(20 \%)$ & $7(26 \%)$ & \\
\hline \multicolumn{5}{|l|}{ Grade } \\
\hline G1 & $48(96 \%)$ & $10(91 \%)$ & $9(60 \%)$ & \multirow[t]{3}{*}{0.002} \\
\hline $\mathrm{G} 2$ & $1(2 \%)$ & $1(9 \%)$ & $4(33 \%)$ & \\
\hline G3 & $1(2 \%)$ & $0(0 \%)$ & $2(13 \%)$ & \\
\hline
\end{tabular}

\section{Clinical Presentation and Treatment}

Of the 141 patients, 98 (69.5\%) presented incidentally on screening colonoscopy. Other clinical presentations included change in bowel habits $(\mathrm{n}=18,12.8 \%)$, rectal bleeding ( $\mathrm{n}=9,6.4 \%)$, abdominal/rectal pain $(\mathrm{n}=7$, $5.0 \%)$, unexplained weight loss $(\mathrm{n}=3,2.1 \%)$, and other $(\mathrm{n}=6,4.2 \%)$. Of the 123 patients with nonmetastatic disease, $94(76.4 \%)$ presented without symptoms. Significantly fewer patients with metastatic disease, only 4 of 18 $(22.2 \%)$, were asymptomatic $(\mathrm{p}<0.001)$.

Treatments were categorized as endoscopy, transanal excision, or open surgery (table 4). There were 11 patients for whom no treatment data were available. Local treatments included endoscopic or transanal excision and accounted for $79.2 \%(\mathrm{n}=103)$ of the cases. Within this group, $80.6 \%(n=83)$ were treated endoscopically, and $19.4 \%(\mathrm{n}=20)$ were treated by transanal excision. The regional treatment group included more invasive surgical procedures and accounted for $20.8 \%(n=27)$ of treatments. When comparing patients with metastatic NETs with patients with nonmetastatic disease, significantly fewer metastatic patients received endoscopic treatment $(\mathrm{p}=0.006)$. Only $28.6 \%(\mathrm{n}=5)$ of metastatic tumors were treated endoscopically, while $64.2 \%(\mathrm{n}=$ 79) of nonmetastatic tumors were treated endoscopically.

\section{Survival Analysis}

The median survival time for all 141 patients was 6.8 years (range, $0.8-34.7$ years). The overall 5-year survival rate was $84.4 \%$ (fig. 1a). The 5-year survival rates for patients in stages I, II, III and IV were 92.7, 75.0, 42.9 and $33.2 \%$, respectively. Kaplan-Meier analysis showed a significant difference in survival according to tumor stage when comparing stage I with stage II tumors $(\mathrm{p}<0.001$; fig. 1b). Analysis between stage II, III and IV tumors showed no statistical difference in survival $(\mathrm{n}=29)$.

Lower tumor grade was also predictive of improved survival as compared to higher tumor grade (fig. 1c). The 5-year survival rates for patients with G1, G2 and G3 tumors were 87.7, 47.6 and 33.3\%, respectively. KaplanMeier analysis and Cox regression showed significant difference between low-grade and either medium- or highgrade tumors ( $\mathrm{p}=0.004$; fig. $1 \mathrm{c}$ ).

Univariate analysis showed significance for stage, grade, size, symptoms and treatment modality (table 5). Multivariate analysis showed that stage alone was statistically significant as the strongest predictor of survival. Estimated cumulative survival was greatest for stage 1 tumors (table 6).

log-rank analysis also showed significant differences between size grouping $<1 \mathrm{~cm}$ and $>1 \mathrm{~cm}(\mathrm{p}<0.001$; fig. 2$)$, but failed to show a difference between groups $1-2 \mathrm{~cm}$ and $>2 \mathrm{~cm}$. There was a significant difference in overall 


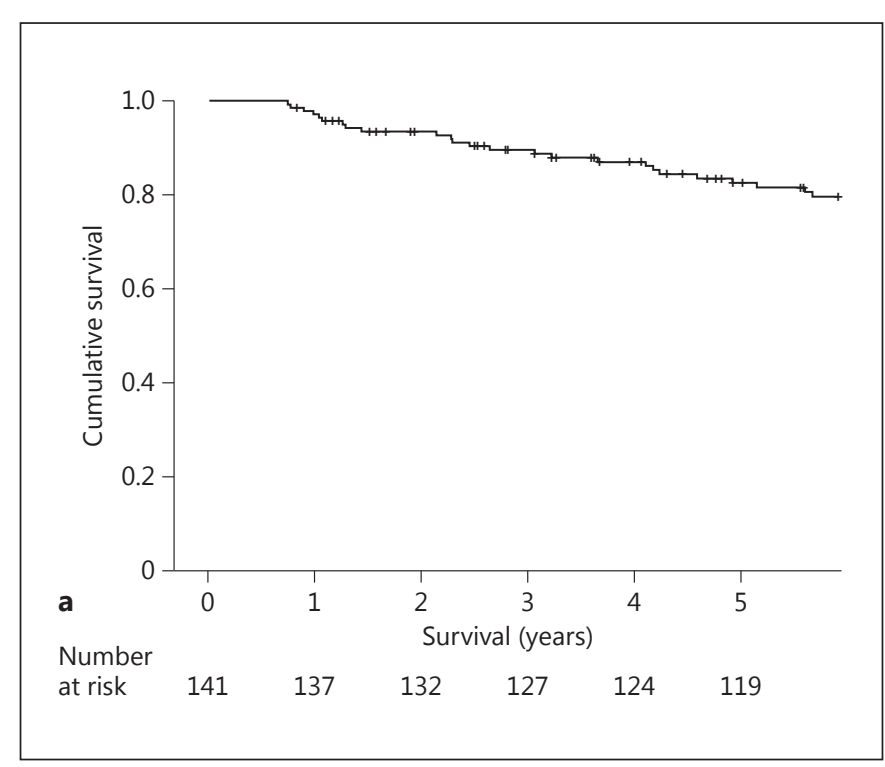

Fig. 1. Kaplan-Meier analysis of survival. a Overall survival of all patients with 5 -year survival rate was $84.4 \%$. b Overall survival by tumor stage. Patients with stage I disease had greater survival than patients with stages II-IV ( $\mathrm{p}<0.001)$. c Overall survival by tumor grade. Patients with grade I disease had greater survival than patients with grades II-III $(\mathrm{p}=0.004)$.

Table 5. Univariable and multivariable analysis

\begin{tabular}{|c|c|c|c|c|}
\hline & \multicolumn{2}{|c|}{ Univariable analysis } & \multicolumn{2}{|c|}{ Multivarable analysis } \\
\hline & $\begin{array}{l}\text { odds } \\
\text { ratio }\end{array}$ & $\begin{array}{l}95 \% \\
\text { confidence } \\
\text { interval }\end{array}$ & $\begin{array}{l}\text { odds } \\
\text { ratio }\end{array}$ & $\begin{array}{l}95 \% \\
\text { confidence } \\
\text { interval }\end{array}$ \\
\hline Stage & 2.543 & 2.27 to 2.81 & 2.478 & 2.06 to 2.89 \\
\hline Grade & 5.992 & 5.22 to 6.76 & 0.902 & 0.44 to 1.35 \\
\hline Size & 1.448 & 1.23 to 1.67 & 0.855 & 0.53 to 1.17 \\
\hline Symptoms & 3.215 & 2.54 to 3.89 & 1.207 & 0.33 to 2.08 \\
\hline Endoscopy & 0.269 & -0.45 to 0.99 & 0.615 & -0.25 to 1.48 \\
\hline
\end{tabular}
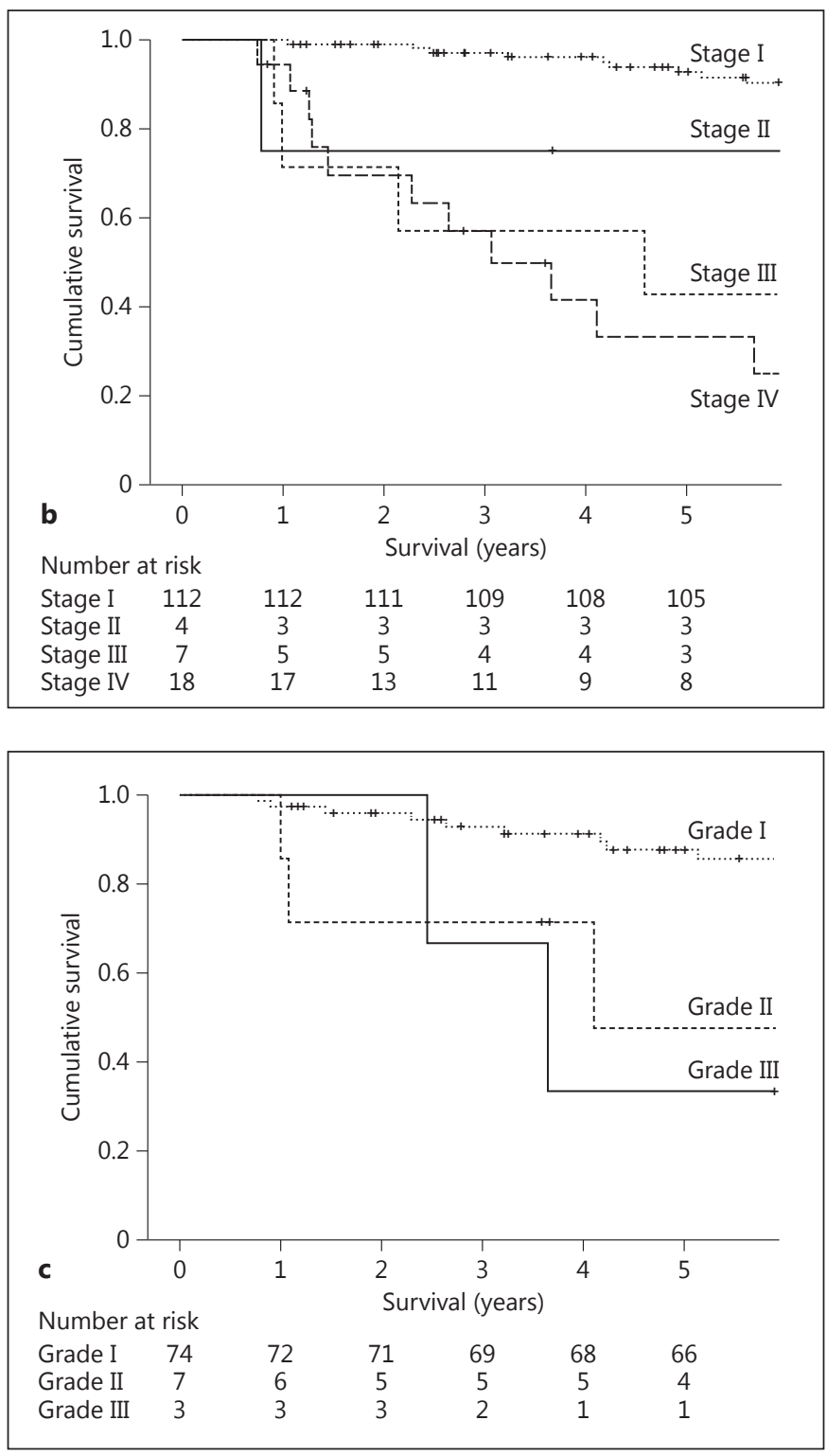

survival time between patients with metastatic tumors and nonmetastatic tumors (average 3.4 vs. 7.9 years, respectively, $\mathrm{p}<0.001$ ).

Kaplan-Meier curves were also generated to look for differences in survival between diagnostic modality groups. Patients who presented without symptoms had a significantly greater overall survival $(\mathrm{p}<0.001)$. Additionally, survival time between treatment groups showed significantly greater survival in patients who were treated endoscopically, with average survival being 8.5 versus 5.9 years $(\mathrm{p}<0.001)$. 
Table 6. Survival characteristics of rectal NETs by stage and grade

\begin{tabular}{lcllll}
\hline & $\begin{array}{l}\text { 1-year } \\
\text { survival, } \%\end{array}$ & $\begin{array}{l}\text { 3-year } \\
\text { survival, } \%\end{array}$ & $\begin{array}{l}\text { 5-year } \\
\text { survival, } \%\end{array}$ & $\begin{array}{l}\text { Estimated cumulative } \\
\text { survival, years }\end{array}$ & $\begin{array}{l}\text { Standard } \\
\text { deviation, years }\end{array}$ \\
\hline Overall survival & 97.2 & 89.6 & 84.4 & 21.7 & 2.9 \\
Stage 1 & 100.0 & 97.2 & 92.7 & 25.8 & 3.5 \\
Stage 2 & 75.0 & 75.0 & 75.0 & 5.5 & 1.9 \\
Stage 3 & 71.4 & 57.1 & 42.9 & 5.8 & 1.8 \\
Stage 4 & 94.4 & 56.9 & 33.2 & 4.0 & 0.7 \\
Grade G1 & 97.3 & 92.8 & 87.7 & 14.1 & 0.7 \\
Grade G2 & 85.7 & 71.4 & 47.6 & 6.4 & 1.8 \\
Grade G3 & 100.0 & 66.7 & 33.3 & 4.0 & 0.8 \\
\hline
\end{tabular}

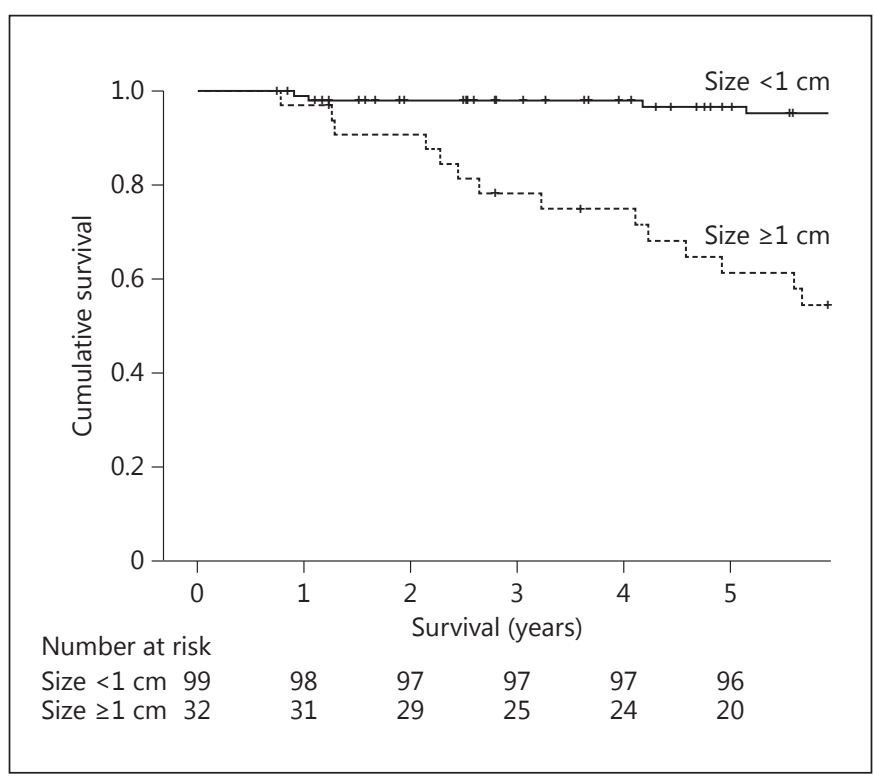

Fig. 2. Kaplan-Meier curve of overall survival by tumor size. Patients with tumors $<1 \mathrm{~cm}$ had greater survival than patients with tumors $\geq 1 \mathrm{~cm}(\mathrm{p}<0.001)$.

\section{Discussion}

Rectal NETs have rapidly increased in incidence, with more than 10-fold rise in the last 30 years [1]. The staging and grading guidelines set by NET societies have not yet been validated in a US tertiary care population. This study represents the first known US validation of the ENETS/ NANETS guidelines for rectal NETs. Overall, 5-year survival rate was $84.4 \%$, consistent with $88 \%$ cited by NET societies and review articles $[1,8,11,14,25]$. In our study using these criteria, tumor stage and grade accurately predicted clinical outcome and survival, with advanced stage and grade associated with worse outcomes in agreement with the confirmatory European study by Jann et al. [23].

Multivariate analysis showed stage to be the strongest predictor of survival. Stage I, II, III and IV tumors accounted for $79.4,2.8,5.0$ and $12.8 \%$, respectively. The 5 -year survival rates for patients in stages I, II, III and IV were 92.7, 75.0, 42.9 and 33.2\%, respectively. Stage I showed statistically significant increase in survival over stage II. It was also significant when compared to stages III and IV. There was no statistical difference in survival between tumors staged II-IV despite an apparent separation in survival curves. There appeared to be trends towards poorer survival for more advanced stage tumors, but this was not statistically significant because of the small number of events.

G1 tumors accounted for $88.1 \%$, G2 8.3\% and G3 3.6\%. The 5-year survival rates for patients with G1, G2 and G3 tumors were $87.7,47.6$ and $33.3 \%$, respectively. In agreement with the consensus guidelines, we found that lowergrade tumors were associated with improved survival as compared to higher-grade tumors. We did not find statistically significant differences in survival between G2 and G3 tumors; this likely reflects the small numbers of G2 and G3 tumors (only 10 tumors in all).

In our study, treatment modality was associated with tumor stage. Stage IV tumors were less frequently treated endoscopically and required more invasive procedures to treat the primary tumor, consistent with ENETS and NANETS staging and treatment recommendations [21, $22]$. Evolving therapies using endoscopic resection and submucosal dissection are treatments reserved for more limited disease and have proven to be effective when warranted [26-29]. The main limiting factor in treatment of localized disease is tumor depth. Positive deep margins on endoscopic biopsy require more invasive treatment. 


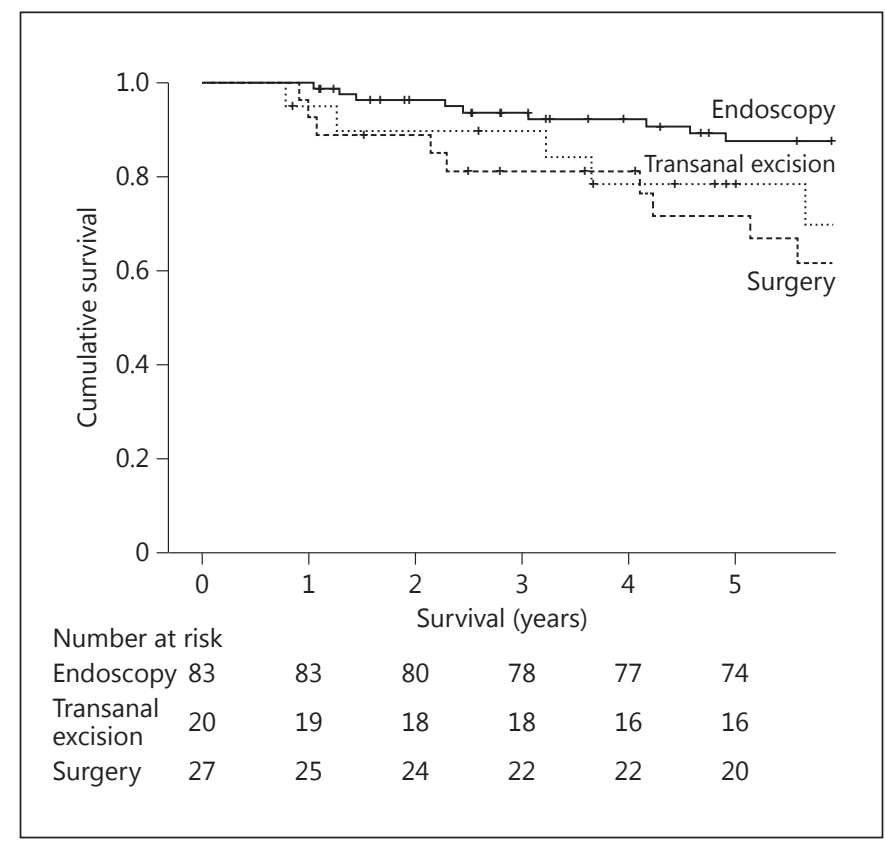

Fig. 3. Kaplan-Meier curve of overall survival by treatment group. Patients who received endoscopic treatment had greater survival than patients treated by transanal excision or surgery $(\mathrm{p}<0.001)$.

Not surprisingly, those patients treated with surgery showed significantly worse survival as this patient population reflected more advanced stage (fig. 3 ).

This study showed that increased tumor size was associated with metastatic disease; the majority $(n=11$, $61 \%$ ) of tumors $>2 \mathrm{~cm}$ demonstrated evidence of distant metastases. Importantly, there is still a small risk of metastasis for NETs $<1 \mathrm{~cm}$. In this study, only 1 of 99 NETs $<1 \mathrm{~cm}$ had metastasized (1.0\%), though figures ranging from 1.7 to $3.4 \%$ have been cited in other studies [12, 30, 31]. This is a small but real risk. Stage IV tumors were also associated with symptomatic presentation at diagnosis.

NETs found on screening colonoscopy were often small and endoscopically resectable. Patients with these tumors had early stage disease and better survival. Still, as screening sigmoidoscopy or colonoscopy becomes more prevalent, these early-stage tumors will likely be more commonly detected as has been suggested by Scherübl [3]. Noninvasive treatment with endoscopy will continue to be a useful treatment for this group of patients. Future studies should address the follow-up necessary for these early-stage patients.

One limitation of this study is the databases included patients treated over nearly 4 decades from 1972 to 2011. In this time, practice patterns have changed. Endoscopic modalities and treatments have become increasingly sophisticated. Endoscopic therapy in our study was largely endoscopic polypectomy or biopsy. Several recent studies have demonstrated the utility of endoscopic mucosal resection and even endoscopic submucosal dissection [26$28,32]$. Results remain divided as to which endoscopic modality might have the best outcomes, with endoscopic mucosal resection having shorter procedure time and endoscopic submucosal dissection having a higher rate of complete resection [26]. In addition, transanal endoscopic microsurgery has only recently become available as a less invasive surgical procedure with high rates of complete resection [33]. Now, localized disease can be treated by transanal procedures that used to require an open surgical approach. Another limitation to the study is that cause of death was not available for deceased patients. This prevents the assessment of disease-specific survival in this population. Additionally, small sample size with lack of events prevented statistically significant outcomes between stage II-IV disease.

\section{Conclusions}

The results of our study validated ENETS/NANETS guidelines for staging and grading of rectal NETs in the US setting of a tertiary referral center. Staging according to ENETS/NANETS guidelines should be used in the treatment algorithm rather than size alone. Additionally, clinicians should be more suspicious of advanced disease if the patient presents symptomatically, in which case tumor grading and special staining can be considered.

\section{Acknowledgements}

The authors of this paper would like to formally acknowledge the assistance of the Carcinoid Cancer Foundation (CCF) for access to the CCF database.

References

1 Lawrence B, Gustafsson BI, Chan A, Svejda B, Kidd M, Modlin IM: The epidemiology of gastroenteropancreatic neuroendocrine tumors. Endocrinol Metab Clin North Am 2011;40:1,18, vii.

2 Niederle MB, Hackl M, Kaserer K, Niederle B Gastroenteropancreatic neuroendocrine tumours: the current incidence and staging based on the WHO and European Neuroendocrine Tumour Society Classification: an analysis based on prospectively collected parameters. Endocr Relat Cancer 2010;17:909-918. 
-3 Scherübl H: Rectal carcinoids are on the rise: early detection by screening endoscopy. Endoscopy 2009;41:162-165.

-4 Shields CJ, Tiret E, Winter DC, International Rectal Carcinoid Study Group: Carcinoid tumors of the rectum: a multi-institutional international collaboration. Ann Surg 2010;252: 750-755.

5 Yoon SN, Yu CS, Shin US, Kim CW, Lim SB, Kim JC: Clinicopathological characteristics of rectal carcinoids. Int J Colorectal Dis 2010;25: 1087-1092.

6 Pinchot SN, Holen K, Sippel RS, Chen H: Carcinoid tumors. Oncologist 2008;13:12551269.

7 Chung TP, Hunt SR: Carcinoid and neuroendocrine tumors of the colon and rectum. Clin Colon Rectal Surg 2006;19:45-48.

8 Yao JC, Hassan M, Phan A, Dagohoy C, Leary C, Mares JE, Abdalla EK, Fleming JB, Vauthey JN, Rashid A, Evans DB: One hundred years after 'carcinoid': epidemiology of and prognostic factors for neuroendocrine tumors in 35,825 cases in the united states. J Clin Oncol 2008;26:3063-3072.

9 Modlin IM, Sandor A: An analysis of 8305 cases of carcinoid tumors. Cancer 1997;79: 813-829.

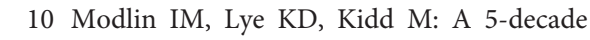
analysis of 13,715 carcinoid tumors. Cancer 2003;97:934-959.

11 Godwin JD 2nd: Carcinoid tumors. An analysis of 2837 cases. Cancer 1975;36:560-569.

12 Landry CS, Brock G, Scoggins CR, McMasters $\mathrm{KM}$, Martin RC 2nd: A proposed staging system for rectal carcinoid tumors based on an analysis of 4701 patients. Surgery 2008; 144 : 460-466.

$\checkmark 13$ Shebani KO, Souba WW, Finkelstein DM, Stark PC, Elgadi KM, Tanabe KK, OTT MJ: Prognosis and survival in patients with gastrointestinal tract carcinoid tumors. Ann Surg 1999;229:815.

14 Konishi T, Watanabe T, Muto T, Kotake K, Nagawa H: Site distribution of gastrointestinal carcinoids differs between races. Gut 2006;55:1051-1052.

-15 Sauven P, Ridge JA, Quan SH, Sigurdson ER: Anorectal carcinoid tumors. Is aggressive surgery warranted? Ann Surg 1990;211:67-71.
16 Rindi G, Kloppel G, Couvelard A, Komminoth P, Korner M, Lopes JM, McNicol AM, Nilsson O, Perren A, Scarpa A, Scoazec JY, Wiedenmann B: TNM staging of midgut and hindgut (neuro) endocrine tumors: a consensus proposal including a grading system. Virchows Arch 2007;451:757-762.

17 Edge SB, Byrd DR, Compton CC, Fritz AG, Greene FL, Trotti A: AJCC (American Joint Committee on Cancer) Cancer Staging Manual, ed 7. New York, Springer, 2010, p 181.

18 Bosman FT, Carneiro F, Hruban RH, Theise ND (eds): WHO Classification of Tumours of the Digestive System, ed 4. Geneva, WHO, 2010.

19 Sobin LH, Gospodarowicz MK, Wittekind C, International Union against Cancer: TNM Classification of Malignant Tumours, ed 7. Hoboken, Wiley-Blackwell, 2009.

20 Konishi T, Watanabe T, Nagawa H, Oya M, Ueno M, Kuroyanagi H, Fujimoto Y, Yamaguchi T, Muto T: Treatment of colorectal carcinoids: a new paradigm. World J Gastrointest Surg 2010;2:153-156.

21 Anthony LB, Strosberg JR, Klimstra DS, Maples WJ, O’Dorisio TM, Warner RR, Wiseman GA, Benson AB 3rd, Pommier RF: The NANETS consensus guidelines for the diagnosis and management of gastrointestinal neuroendocrine tumors (NETs) well-differentiated NETs of the distal colon and rectum. Pancreas 2010;39:767-774.

22 Caplin M, Sundin A, Nillson O, Baum RP, Klose KJ, Kelestimur F, Plockinger U, Papotti M, Salazar R, Pascher A: ENETS consensus guidelines for the management of patients with digestive neuroendocrine neoplasms: colorectal neuroendocrine neoplasms. Neuroendocrinology 2012;95:88-97.

23 Jann H, Roll S, Couvelard A, Hentic O, Pavel M, Muller-Nordhorn J, Koch M, Rocken C, Rindi G, Ruszniewski P, Wiedenmann B, Pape UF: Neuroendocrine tumors of midgut and hindgut origin: tumor-node-metastasis classification determines clinical outcome. BMC Cancer 2011;117:3332-3341.
24 Bernick PE, Klimstra DS, Shia J, Minsky B, Saltz L, Shi W, Thaler H, Guillem J, Paty P, Cohen AM, Wong WD: Neuroendocrine carcinomas of the colon and rectum. Dis Colon Rectum 2004;47:163-169.

-25 Koura AN, Giacco GG, Curley SA, Skibber JM, Feig BW, Ellis LM: Carcinoid tumors of the rectum: effect of size, histopathology, and surgical treatment on metastasis free survival. Cancer 1997;79:1294-1298.

26 Zhong DD, Shao LM, Cai JT: Endoscopic mucosal resection (EMR) versus endoscopic submucosal dissection (ESD) for rectal carcinoid tumours: a systematic review and meta-analysis. Colorectal Dis 2013;15:283-291

27 Jeon SM, Lee JH, Hong SP, Kim TI, Kim WH, Cheon JH: Feasibility of salvage endoscopic mucosal resection by using a cap for remnant rectal carcinoids after primary EMR. Gastrointest Endosc 2011;73:1009-1014.

28 Choi CW, Kang DH, Kim HW, Park SB, Jo WS, Song GA, Cho M: Comparison of endoscopic resection therapies for rectal carcinoid tumor: endoscopic submucosal dissection versus endoscopic mucosal resection using band ligation. J Clin Gastroenterol 2013;47: 432-436.

29 Lee WH, Kim SW, Lim CH, Kim JS, Cho YK, Lee IS, et al: Efficacy of endoscopic mucosal resection using a dual-channel endoscope compared with endoscopic submucosal dissection in the treatment of rectal neuroendocrine tumors. Surg Endosc 2013, E-pub ahead of print.

30 Christensen M, Bulow S: Carcinoid tumors of the colon and rectum. Ugeskr Laeger 1998; 160:4605-4609.

31 Kulke MH, Mayer RJ: Carcinoid tumors. N Engl J Med 1999;340:858-868.

32 Kim KM, Eo SJ, Shim SG, Choi JH, Min BH, Lee JH, et al: Treatment outcomes according to endoscopic treatment modalities for rectal carcinoid tumors. Clin Res Hepatol Gastroenterol 2013;37:275-282.

33 Son HJ, Sohn DK, Hong CW, Han KS, Kim BC, Park JW, et al: Factors associated with complete local excision of small rectal carcinoid tumor. Int J Colorectal Dis 2013;28:5761.
Prognostic Features of Rectal

Neuroendocrine Tumors
Neuroendocrinology 2013;98:180-187 DOI: $10.1159 / 000355612$ 